\title{
The importance of literacy in research and in practice
}

\author{
Rima E Rudd
}

Research over the past few decades has established strong links between educational attainment and health outcomes, especially for patients with chronic disease. Arthritis studies have contributed to this substantial body of literature; for example, patients with rheumatoid arthritis who had not completed high school showed poorer clinical status than patients who had, and a low level of formal education was a predictor of premature mortality for patients over a 10-year period. At the same time, however, pathways from education to health outcomes have not, until recently, been fully explored. Researchers in the nascent field of health literacy who hypothesized that literacy might be one of the key pathways have found strong associations between literacy skills and a variety of health outcomes (Rudd RE, Health Literacy Research and Policy [www.hsph.harvard.edu/ healthliteracy], accessed June 6, 2007).

US Department of Education findings from the 1992 National Adult Literacy Survey and the 2003 National Assessment of Adult Literacy indicate that most adults, though able to read, are constrained in their ability to use printed materials, which can limit their participation in today's society and economy. Adults have even more difficulty understanding health-related materials. Some of this difficulty is the responsibility of the health sector: approximately 800 of the 1,000 or so peer-reviewed published health literacy studies that focus on assessments of health materials indicate that most are written at levels that far exceed the reading skills of average US adult high school graduates. These materials include those related to informed consent, medication directions, and arthritis-related information.

The well-documented mismatch between the literacy skills of patients and the literacy demands of health-care systems have serious implications for rheumatology practice and research. Patients with arthritis need sophisticated literacy skills: they are expected to read prose to understand their diagnosis and
Rheumatologists

should take

action to lower

literacy burdens

and reduce

literacy-related

barriers to care

RE Rudd is a Senior

Lecturer in the

Department of Society,

Human Development

\& Health at Harvard

School of Public

Health, Boston,

MA, USA.

\section{Competing interests}

The author declared no

competing interests.

www.nature.com/clinicalpractice doi:10.1038/ncprheum0576 treatment options, to comprehend documents such as prescription labels, to use tools such as clocks and calendars to manage medicines, to find words to describe changes in their symptoms, as well as to follow the rheumatologist's words in discussions. Along the way, they navigate the corridors and paper work of institutions to gain access, agree to undergo procedures, maintain coverage, or take part in research.

Words do get in the way. The Institute of Medicine (IOM Committee on Health Literacy (2004) Health Literacy: a prescription to end confusion. Washington, DC: National Academies Press) and the Joint Commission (The Joint Commision (2007) "What did the doctor say?": Improving health literacy to protect patient safety) recommend the use of plain language in written materials and in verbal communication. Rheumatologists should, therefore, use common, everyday words in place of medical terms and professional jargon in speech and in print. Furthermore, the literature suggests that 'teach back' methods are helpful. Here, practitioners providing information and researchers engaging in informed consent processes are encouraged to ask the listeners to describe what they will tell to a friend or family member when they get home to help them check on the clarity of the discussion. Those who develop educational materials are reminded to use commonly available readability assessment tools, to pilot test with members of the intended audiences, and perhaps apply new technologies that combine print with visual and auditory features.

Rheumatologists should take action to lower literacy burdens and reduce literacy-related barriers to care. Furthermore, studies and related insights that focus on health literacy and arthritis outcomes could offer a profound contribution to the growing field of health literacy studies and, more importantly, could support research efforts and enhance best practice in rheumatology. 